\title{
COMENTÁRIO: A FILOSOFIA EXPERIMENTADA NO TEMPO E NA DIFERENÇA
}

\author{
Viviane Cristina Cândido ${ }^{1}$
}

Referência do texto comentado: PERIUS, Oneide. A multiplicidade originária: uma leitura da filosofia de Franz Rosenzweig. Trans/Form/Ação: revista de filosofia da Unesp, vol. 43, n. 4, p. 255-270, 2020.

Oneide Perius nos convida a conhecer o pensamento de Franz Rosenzweig, um dos filósofos mais importantes do século XX, a partir de sua obra A Estrela da Redenção. Neste comentário, visando a contribuir com esse importante desafio, tecemos algumas consideraçôes acerca de três conceitos fundamentais para esse autor - experiência, tempo e finitude - e acerca de sua condição como judeu.

Em 1936, Walter Benjamin (1985, p. 199) destacou Nikolai Leskov como um narrador por excelência, o qual "[...] retira da experiência o que ele conta: sua própria experiência ou a relatada pelos outros. E incorpora as coisas narradas à experiência dos seus ouvintes." Anos antes, em 1929, ano da morte de Rosenzweig, havia afirmado ser $A$ Estrela da Redenção "uma das pouquíssimas obras que ainda valiam a pena serem lidas". O que teriam em comum Leskov e Rosenzweig?

A Experiência. Em seu Novo Pensamento (1925), publicado, segundo seu autor, como uma resposta àqueles que aceitaram $A$ Estrela da Redenção, ou

1 Professora adjunta do Centro de História e Filosofia das Ciência da Saúde (CeHFi) - Escola Paulista de Medicina (EPM) - Universidade Federal de São Paulo, São Paulo, Brasil. Doutora em Ciências da Religião pela Pontifícia Universidade Católica de São Paulo. Mestra em Educação. Graduada em Filosofia e Pedagogia. São Paulo, SP, Brasil.

https://orcid.org/0000-0002-4164-0245 E-mail: candido.viviane@unifesp.br.

http://dx.doi.org/10.1590/0101-3173.2020.v43n4.16.p271

This is an open-access article distributed under the terms of the Creative Commons Attribution License. 
seja, àqueles que queriam dialogar com ele, Rosenzweig afirma que o ponto culminante do $1^{\circ}$ Volume da Estrela é mostrar que nenhum dos três grandes conceitos fundamentais do pensamento filosófico - Deus, Mundo e Homem - pode ser reduzido ao outro. O que deles sabemos de modo mais exato, tomados por si mesmos, nós o sabemos com o saber intuitivo da experiência, e o que deles podemos conhecer é sua realidade efetiva.

Sobre a experiência e a facticidade, a realidade efetiva experimentada, da qual tratará especificamente no segundo volume da Estrela, Rosenzweig (2005, p. 27) assinala:

A experiência, portanto, não experimenta coisas, as quais por certo se tornam visíveis como facticidades últimas, mais além da experiência por obra do pensamento; mas o que ela experimenta, experimenta nestas facticidades.

Trata-se da proposição de uma filosofia experimentada, a qual, ao invés de retirar Deus, Mundo e Homem de sua contingência, lançando-os ou para a supervalorização de suas individualidades, ao isolá-los, ou para a abstração, a que está fadado todo aquele que é retirado da contingência, entende que essas três potências só podem ser conhecidas em suas realidades efetivas - suas relaçóes.

Em seu livro $O$ senso comum são e enfermo - O Livrinho, publicado em 1921, Rosenzweig (2001) descreve o ataque de paralisia a que é submetido o filósofo, no momento em que este, desacreditando do senso comum, começa a se perguntar sobre o que as coisas são, considerando tais perguntas como de suma importância, perguntas últimas. Em sua rigidez, quer a solução hoje mesmo, no momento do assombro, e acaba acometido por uma paralisia e, dessa forma, exclui esse seu estado, de estar assombrado, bem como aquilo que lhe causou esse assombro e, consequentemente, a si mesmo da corrente da vida que segue fluindo. Assim, afirma a relação como condição para o conhecimento das três grandes potências, as quais não se dão $\mathrm{em}$ si - em sua essência, mas somente em suas relaçôes.

O tempo. Perius (2020, p. XXXX) assevera: "A lógica da totalidade leva, no limite à aniquilação do outro" e "não pode ser a lógica da filosofia." O Novo Pensamento impóe a necessidade do outro, pressupondo que pensamos e falamos para alguém que, por sua vez, também pensa e fala “[...] esse alguém é sempre um alguém inteiramente determinado e, diferentemente do público 
em geral, não tem meramente orelhas, e sim também boca”, frisa Rosenzweig (2005, p. 34-35). Em outras palavras, o outro é um outro exatamente porque fala, do que decorre a perspectiva dialógica do pensamento rosenzweiguiano.

Ao abordar a narrativa como método, no segundo volume da Estrela, destaca essa temporalidade do Novo Pensamento: "Precisamente o tempo chega a ser para o narrador inteiramente real. Não o tempo em que algo acontece, e sim o que por si mesmo acontece", e mais adiante "A essência não quer saber nada do tempo". (ROSENZWEIG, 2005, p.29)

No tempo, a pergunta de um é a resposta do outro, como enfatiza em seu Livrinho: "Sou questionado por pessoas" - ou seja, Rosenzweig aponta para a concretude, o que significa reconhecer o tempo da pergunta de um e resposta do outro - a relação, do que decorre a Filosofia tratar da multiplicidade, da pluralidade e, consequentemente, da diferença, ao contrário da modernidade, a qual reduz o real a uma perspectiva totalitária, bem como a uma pretensa igualdade.

A Finitude. Rosenzweig (2005, p. 31) afirma:

Para um médico que está tratando um caso, o tratamento é o presente, a enfermidade é o passado e a constatação da morte é o futuro" e continua "e não teria nenhum sentido que ele, para obedecer a um tic do conhecimento atemporal, quisesse excluir do diagnóstico o saber e a experiência, da terapia a audácia e a obstinação, do prognóstico o temor e a esperança.

Rosenzweig (2001) apresenta a morte como acontecimento, como lugar de significação, na medida em que é ela que desafia a vida a viver bem, sabedora de sua finitude. O homem sábio sabe que vai morrer e deixa que a morte caminhe ao seu lado e, por isso, é capaz da ação no tempo. É capaz de reconhecer que o instante - o tempo que lhe é dado para agir - lhe é gratuito, é a sua sempre eternidade, é o lugar da possibilidade.

A morte aqui é empiria, a certeza de nossa finitude, de sorte que o reconhecimento dos limites que isso impóe é antídoto para as pretensōes do Homem moderno, que reduz Deus e o Mundo ao Eu, lugar da autossuficiência, da onipotência, do ego. É com a compreensão da morte que podemos chegar à Vida, esse é o caminho da Estrela. De um lado, o homem é homem, porque é mortal: a finitude não é uma possibilidade, mas uma certeza; de outro, numa 
perspectiva mais ampla e que, por sua vez, póe em xeque a totalidade - a morte é para o indivíduo, ou seja, quem morre é o homem solitário e não a totalidade, consequentemente, a filosofia que considera a totalidade não considera o homem. $\mathrm{O}$ homem morre, o todo náo.

O judeu. Finalmente, ainda em seu Novo Pensamento, declara que A Estrela da Redenção não é um livro judaico, mas um sistema de Filosofia. $\mathrm{O}$ pensamento rosenzweiguiano é impregnado de uma perspectiva judaica, indissociável do seu pensamento. Pierre Bouretz (2011, p. 149) ressalta: "A experiência filosófica de Franz Rosenzweig parece de tal maneira imbricada na trama histórica de sua época e na carne de quem a viveu que é, à primeira vista, quase impossível dissociá-las." Também não podemos dissociá-lo da sua condição de judeu, que, na perspectiva de uma filosofia da religião, significa dizer que o seu pensamento é marcado por sua experiência religiosa, dialoga com ela.

Esse diálogo se evidencia nas categorias que escolhe para explicitar a sua compreensão do tempo: "Na eternidade do sempre permanente o tempo significa o permanente e a duração; na eternidade do sempre renovado ele é o tempo do novo, do sempre renovável; na eternidade do eterno, o tempo significa propriamente a conexão entre duas eternidades" - Tempos e Eternidades da Criação, da Revelação e da Redenção.

Se, de um lado, podemos entender as palavras acima como "religiosas", vejamos sua nota, escrita em 1922: “[...] a revelação é uma 'antireligião’ que não só não sacraliza o mundo como o faz o paganismo, mas também rasga o véu que as religiôes instituídas interpóem entre a natureza e Deus" (BOURETZ, 2011, p. 180). É possível perceber as referências de sua experiência religiosa para construir seu sistema filosófico que, todavia, não significa um sistema religioso. A propósito, salienta Batnitzky (2011, p. 73): "Experiência, e não racionalidade, eles argumentam [Buber e Rosenzweig], é a base da vida judaica."

Rosenzweig (2005, p. 53) acrescenta:

A relação verdadeira entre ambas disciplinas [filosofia e teologia] é fraternal em sua nova forma e inclusive deve levar à fusão numa mesma pessoa àqueles que as praticam. Os problemas teológicos querem ser traduzidos em termos humanos e os humanos elevados até o nível da teologia. 
Por se tratar da Vida, há lugar para ambas as disciplinas, como afirma em outra de suas notas de 1922: "A revelação sobrepuja a morte, cria e institui em seu lugar a morte redentora. Aquele que ama não crê mais na morte e não crê mais do que na morte" (BOURETZ, 2011, 181). De que outra maneira tratar o mais humano dos temas?

\section{REFERÊNCIAS}

BATNITZKY, Leora. How Judaism Became a Religion: An Introduction to Modern Jewish Thought. Princeton: Princeton University Press, 2011.

BENJAMIN, Walter. O Narrador - Consideraçôes sobre a obra de Nikolai Laskov.

Magia e técnica, arte e política - ensaios sobre literatura e história da cultura. São Paulo: Editora Brasiliense, 1985. 197-221

BOURETZ, Pierre. Testemunhas do futuro: filosofia e messianismo. São Paulo: Perspectiva, 2011.

CÂNDIDO, Viviane C. Imanência e transcendência em Franz Rosenzweig contribuiçôes da Filosofia da Religiáo para as Ciências da Saúde. Estudos de Religiáo, v.34, n.2, p.151-176, maio-ago, 2020.

ROSENZWEIG, Franz. El libro del sentido común sano y enfermo. Madrid: Caparrós Editores, 2a. ed., 2001.

ROSENZWEIG, Franz. El Nuevo Pensamiento. Buenos Aires: Adriana Hidalgo Editora, 2005. 
CÂNDIDO, V. C.

Recebido: 12/10/2019

Aceito: 26/02/2020 